\title{
Effect of different growth conditions on certain biochemical parameters of different cyanobacterial strains
}

\author{
Sherif H. $\underline{\text { Hassan }}^{1,2^{\star}}$, Mohamed S. Abdel Hameed ${ }^{1,3}$, Ola E. $\underline{\text { Hammouda }}^{1}$, Fekry M. $\underline{\text { Ghazal }}^{4}$ and Seham M. \\ Hamed $^{4}$ \\ ${ }^{1}$ Botany Department, Faculty of Science, Beni-Suef University, Egypt \\ ${ }^{2}$ Department of Medical Laboratory Science, College of Applied Medical Science, Al Jouf University, KSA \\ ${ }^{3}$ Biology department, Faculty of Science, Jazan University, KSA \\ ${ }^{4}$ Soils, Water and Environ. Inst., Agric. Res. Center, Giza, Egypt \\ E.mail: abood127@yahoo.com
}

Received 29 ${ }^{\text {th }}$ April 2012; Received in revised form $30^{\text {th }}$ May 2012; Accepted $5^{\text {th }}$ June 2012

\begin{abstract}
Aims: Variation in the traditional growth medium conditions to enhance the production of lipids, carbohydrates, protein and the free amino acids content of three cyanobacterial species.

Methodology and Results: Three species of cyanobacteria (Anabaena laxa, Anabaena fertilissima and Nostoc muscorum) were collected from the culture collection of Soils, Water and Environment Research Institute, Agriculture Research Center, Giza, Egypt, to investigate their biochemical composition under different growth conditions, using $\mathrm{BG} 11_{0}$ (nitrogen free) as growth medium. These conditions were represented by control medium, static glucose medium with $(1 \%, \mathrm{w} / \mathrm{v})$, aerated medium (aerated by bubbling technique depending on $\mathrm{CO}_{2}$ normally existed in air with a concentration of $0.03 \%)$, molasses medium $(0.7 \%, \mathrm{v} / \mathrm{v})$ and aerated medium enriched with glucose $(1 \%$, w/v). Lipid content, total carbohydrates, soluble proteins and free amino acids were determined at the previous conditions. Glucose at $0.7 \%(\mathrm{w} / \mathrm{v})$ was the most favorable for lipid production in $A$. laxa, where it exhibited the highest lipid content $(427 \mu \mathrm{g} / \mathrm{g}$ fresh wt.). Increasing molasses concentration up to $0.7 \%(\mathrm{v} / \mathrm{v})$ produced an increase in lipid contents of the tested cyanobacterial strains. The highest lipid content of both $N$. muscorum (366.2 $\mu \mathrm{g} / \mathrm{g}$ fresh wt.) and $A$. laxa (357.4 $\mu \mathrm{g} / \mathrm{g}$ fresh wt.) were recorded at molasses concentrations of 0.1 and $0.7 \%(\mathrm{v} / \mathrm{v})$, respectively. $A$. laxa expressed high significant values for both proteins $(31.6 \mu \mathrm{g} / \mathrm{mL})$ and free amino acids $(40.5 \mathrm{mg} / \mathrm{g}$ dry wt.) after 6 days of incubation period under aerated enriched glucose condition $(1 \%, \mathrm{w} / \mathrm{v})$. Also, at the same growth conditions, $A$. fertilissima exhibited high significant values for carbohydrates at $4^{\text {th }}$ day $(876.8 \mathrm{mg} / \mathrm{g}$ dry wt.).

Conclusion, significance and impact of study: Aerated enriched glucose medium (1\%, w/v) was the best growth medium condition used in the present study.
\end{abstract}

Keywords: Cyanobacteria; mixotrophy; autotrophy; biochemical parameters

\section{INTRODUCTION}

Algae sequester significant quantity of carbon from atmosphere and industrial gases and were very efficient in utilizing the nutrients from industrial effluents and municipal wastewater. Therefore, cultivation of algal biomass provide dual benefit; production of biofuels and save our environment from air and water pollution (Singh and Olsen, 2011). Mixotrophic culture was a potential mode for mass production of microalgae and cyanobacteria by using heterotrophic capability of the photosynthetic microorganisms (Marquez et al., 1995; Chen, 1997). It was expected that mixotrophic growth can achieve high cell densities and synthesize light-induced products such as photosynthetic pigments and was especially suitable for the production of high value bioactive compounds, fine chemicals and pharmaceuticals. Cyanobacteria possess several advantages as organisms for bio-industrial processes, including simple input requirements, tolerance of marginal agricultural environments, rapid genetics, and carbonneutral applications that could be leveraged to address global climate change concerns (Ducat et al., 2011). Some microalgae and cyanobacteria, which were regarded as obligate photoautotrophs, can utilize organic carbon compounds for their growth (Droop, 1974; Tuchman, 1996). Nostoc spp. assayed can grow mixotrophically by using; glucose, sucrose, and sugarcane molasses as organic substrates, and a greater production of biomass and phycobiliproteins can be reached when compared with the autotrophic growth (Borsari et al., 2007). Most bio-industrial processes rely on microorganisms metabolizing carbohydrate compounds to generate a diverse array of valuable chemicals, such as amino acids, vitamins and organic acids (Ducat et al., 2011). Sugarcane molasses (byproduct of sucrose production) is the most inexpensive raw material widely used for fermentation in the world. Egypt has more than 250-300 thousand feds planted with sugar cane. Moreover waste molasses hydrolysate was 
confirmed as a sole source of full nutrients to totally replace glucose-based medium in support of rapid growth and high oil yield from algae. Also, the quality of biodiesel from waste molasses-fed algae was probably comparable to that from glucose-fed ones (Yan et al., 2011). Inexpensive Spirulina reactors that are capable of producing 10 folds of the biomass of soybeans, while utilizing equivalent amounts of water (Habib et al., 2008). This study aimed to investigate the capability of Anabaena laxa, Anabaena fertilissima and Nostoc muscorum to grow in mixotrophic culture, testing glucose and molasses sugarcane as organic carbon substrates.

\section{MATERIALS AND METHODS}

\section{Strains and growth medium}

Anabaena laxa (Rabenhorst) Braun A., Anabaena fertilissima Rao C.B. and Nostoc muscorum Agardh C. were provided from the culture collection of Soils, Water and Environment Research Institute, Agriculture Research Center, Giza, Egypt. The culture growth medium was BG110 (nitrogen free) (Allen's and Stanier, 1968). The isolates were grown autotrophically and axenically in batch cultures under $28 \pm 2{ }^{\circ} \mathrm{C}$ with continuous illumination at intensities of 2500 LuX.

\section{Growth conditions}

The investigated cyanobacterial strains were sub-cultured, separately, in $5 \mathrm{~L}$ Erlenmeyer bottles, containing $3 \mathrm{~L}$ BG110 medium (nitrogen free) inoculated with $30 \mathrm{~mL}$ of pre-cultured isolates during exponential phase. These strains were cultured under two different growth conditions; autotrophic and mixotrophic. The autotrophic conditions were represented by static and aerated control BG110 medium (aeration was provided by bubbling air at regular pressure, $200 \mathrm{~mL} \mathrm{~min}^{-1}$ and frequency $50 \mathrm{~Hz}$ ), that depended on $\mathrm{CO}_{2}(0.03 \%)$ which exist normally in air. The mixotrophic growth conditions that depended on organic carbon sources (glucose and molasses of sugarcane) were created by adding glucose $(1 \%, \mathrm{w} / \mathrm{v})$ and molasses of sugarcane $(0.7 \%, \mathrm{v} / \mathrm{v})$ separately to the growth media under static condition (without aeration). The last one was formed by adding glucose $(1 \%, w / v)$ to the growth medium under aerated condition.

\section{Sampling and analysis}

Samples of $250 \mathrm{~mL}$ every two days intervals from each of the experimental conditions were harvested by centrifugation at $4000 \mathrm{rpm}$ for $15 \mathrm{~min}$. The pellet was rinsed three times and re-suspended in sterilized distilled water to remove traces of growth medium (Roger and Burns, 1994). These samples were taken to determine carbohydrates, proteins and free amino- $\mathrm{N}$ acids. Carbohydrates were quantified as glucose by anthron technique according to Yemm and Willis (1954). The Total soluble proteins were quantitatively determined using the method described by Lowry et al. (1951). Estimation of free amino- $\mathrm{N}$ in a protein free sample using ninhydrine reagent, was suggested by Lee and Takahashi (1966).
Total lipid content was determined by phosphovaniline method (Barnes and Blackstock, 1973).

Effect of different glucose and molasses
concentrations on lipids

Our future work aimed to study the efficiency of a cyanobacterial strain to produce biofuel, so we were interested in studying the effect of different carbon sources on production of lipids. This experiment was carried out in order to study the effect of different glucose concentrations $(0.1,0.3,0.5,0.7$ and $1 \%, w / v)$ and different molasses concentrations of sugarcane $(0.1,0.3$, $0.5,0.7$ and $1 \%, v / v)$ on total lipid content at the stationary phase for each cyanobacterial species.

\section{Statistical analysis}

The obtained results were analyzed for statistical significant between control and treated groups by using one-way analysis of variance (ANOVA, SPSS 16.0.Ink program). Values were expressed as mean $( \pm)$ standard deviation and values of $\mathrm{P} \leq 0.05$ were statistically significant.

\section{RESULTS}

Table 1 showed that increasing glucose concentration up to $1 \%(\mathrm{w} / \mathrm{v})$ led to the increase in lipid content of the all tested cyanobacterial strains. Where, Anabaena laxa recorded the highest lipid content $\left(427.1 \mathrm{\mu g} \mathrm{g}^{-1}\right.$ fresh wt.) in glucose medium condition $(0.7 \%, w / v)$. Also, by increasing molasses concentration up to $0.7 \%(\mathrm{v} / \mathrm{v})$ led to the increase in lipid content of the tested strains (Table 2). $N$. muscorum showed the highest significant difference of lipid content $\left(366.2 \mu^{-1}\right.$ g gresh wt.) under $0.1 \%$ dose in comparable to the other tested cyanobacterial strains. No growth was recorded at levels higher than $0.1 \%(\mathrm{v} / \mathrm{v})$ of molasses. A. laxa recorded high significant lipid values under $0.7 \%$ dose $\left(357.4 \mu_{\mathrm{g} \mathrm{g}}{ }^{-1}\right.$ fresh wt.). At high level of molasses ( $1 \%, \mathrm{v} / \mathrm{v})$, A. fertilissima exhibited no growth, moreover total lipid content of $A$. laxa decreased markedly.

Data in Table 3 showed that the total carbohydrates of the tested cyanobacterial species in the mixotrophic growth media (static glucose, molasses treatments and aerated enriched glucose medium) greatly exceeded other autotrophic conditions (control, aerated medium). A. laxa reached its maximum value of carbohydrate content (609.2 $\mathrm{mg} \mathrm{g}^{-1}$ dry wt.) after 4 days under static glucose medium which was about 2.8 folds of zero time. Aerated enriched glucose medium was in the second level, followed by molasses treatment. Carbohydrate content of $A$. fertilissima increased gradually during exponential phase to reach its maximum value during stationary phase then declined gradually. The maximum significant value of carbohydrate was about 2.9 folds of zero time that was achieved under aerated enriched glucose medium and followed by static glucose medium which was about 2.3 folds as zero time. While the minimum values were obtained at both air mixture and control media conditions. 
Table 1: Effect of different glucose concentrations on total lipid contents of Anabaena laxa, Anabaena fertilissima and Nostoc muscorum, measured as $\mu_{\mathrm{g} \mathrm{g}}{ }^{-1}$ fresh weight at stationary phase for each species.

\begin{tabular}{llllllcc}
\hline Microalgal & Control & $0.1 \%$ & $0.3 \%$ & $0.5 \%$ & $0.7 \%$ & $1 \%$ & LSD \\
\hline Anabaena laxa & $162.9 \pm 7.4$ & $234.0 \pm 6.8$ & $252.3 \pm 5.6$ & $289.8 \pm 5.4$ & $427.1 \pm 23.5$ & $364.7 \pm 6.7$ & 9.2 \\
Anabaena fertilissima & $37.4 \pm 3.3$ & $71.3 \pm 3.5$ & $81.4 \pm 1.7$ & $135.9 \pm 14.2$ & $154.8 \pm 15.8$ & $170.3 \pm 4.7$ & 7.5 \\
Nostoc muscorum & $228.8 \pm 2.0$ & $236.4 \pm 9.7$ & $241.7 \pm 10.3$ & $259.3 \pm 3.7$ & $275.3 \pm 3.2$ & $278.3 \pm 7.6$ & 5.7 \\
LSD & 3.9 & 5.9 & 5.6 & 7.4 & 13.5 & 5.3 & \\
\hline
\end{tabular}

LSD; the least significant difference at $P \leq 0.05$. Values are means of 3 replicates $\pm S D$

Table 2: Effect of different molasses concentrations on total lipid contents of Anabaena laxa, Anabaena fertilissima and Nostoc muscorum, measured as $\mathrm{\mu g} \mathrm{g}^{-1}$ fresh weight at stationary phase for each species.

\begin{tabular}{llllllll}
\hline Microalgal & Control & $0.1 \%$ & $0.3 \%$ & $0.5 \%$ & $0.7 \%$ & $1 \%$ & LSD \\
\hline Anabaena laxa & $168.9 \pm 7$ & $167.3 \pm 1.9$ & $232.5 \pm 3.3$ & $283.2 \pm 7.7$ & $357.4 \pm 11.1$ & $292.6 \pm 2.8$ & 5.3 \\
Anabaena fertilissima & $52.4 \pm 7$ & $67.8 \pm 1.7$ & $94.7 \pm 8.9$ & $95.0 \pm 2.6$ & $109.9 \pm 5$ & 0 & 4.3 \\
Nostoc muscorum & $224.1 \pm 10.2$ & $366.2 \pm 10.8$ & 0 & 0 & 0 & 0 & 5.0 \\
LSD & 6.7 & 5.2 & 4.5 & 3.9 & 5.8 & 1.3 & \\
\hline
\end{tabular}

LSD; the least significant difference at $\mathrm{P} \leq 0.05$. Values are means of 3 replicates $\pm \mathrm{SD}$

Similarly, $N$. muscorum exhibited more or less the same pattern of the previously mentioned cyanobacterial strains behaviors, where total carbohydrate content increased gradually with time and maximum values were obtained at stationary phase then the recorded values began to decline. Meanwhile, it showed no growth on molasses medium at concentration of $0.7 \%(\mathrm{v} / \mathrm{v})$. The effect of different growth conditions on total soluble protein of $A$. laxa, A. fertilissima and $N$. muscorum, were recorded at different incubation periods.

The total soluble protein increased gradually during growth phase till it reached its maximum content in stationary phase for all growth conditions and for the three organisms except for $A$. laxa under molasses medium where the highest value was obtained at exponential phase (Table 4). A. laxa recorded high significant soluble protein under aerated enriched glucose medium after 6 days which was about 13.2 folds of zero time and followed by aerated medium treatment that exceeded 8.6 folds of zero time. While the minimum protein value was recorded under glucose medium. With regard to $A$. fertilissima the highest soluble protein value was under static glucose and followed by aerated medium to record about 12.2 and 8.2 folds of zero time, respectively. Regarding to $N$. muscorum, the highest soluble protein content was shown after 6 days for all growth media while, the highest one was in the aerated medium and exceeded 27.9 folds of zero time. The changes in total free amino acids content of $A$. laxa, $A$. fertilissima and $N$. muscorum in response to different growth conditions are presented in Table 5. A. laxa the maximum free amino acids $40.5 \mathrm{mg} \mathrm{g}^{-1}$ dry wt. which exceeded 3.26 folds of zero time at $6^{\text {th }}$ day under aerated enriched glucose, followed by $18.2 \mathrm{mg} \mathrm{g}^{-1}$ dry wt. under static glucose medium at the same time interval and exceeded 1.4 folds of zero, followed by $13.5 \mathrm{mg} \mathrm{g}^{-1}$ dry wt. at $6^{\text {th }}$ day in the control medium. $A$. laxa produced the minimum content of free amino acids under both aerated and molasses medium which exhibited gradual decline during incubation periods compared to zero time.

With respect to $A$. fertilissima, data in Table 5 showed that the free amino acids content increased gradually during growth phase and reached its highest value at stationary phase $35.3 \mathrm{mg} \mathrm{g}^{-1}$ dry wt. about 7.9 folds of zero time obtained under molasses at $6^{\text {th }}$ day followed by $29.7 \mathrm{mg} \mathrm{g}$ 1 dry wt. and exceeded 6.6 folds of zero time was produced at $4^{\text {th }}$ day under static glucose medium, $A$. fertilissima produced minimum content of free amino acids $7.1 \mathrm{mg} \mathrm{g}^{-1}$ dry wt. at $4^{\text {th }}$ day under control medium. With regard to $N$. muscorum, as it appeared from Table 5, free amino acids increased gradually during growth phase till reached its highest values at stationary phase, for control, static glucose and aerated enriched glucose medium, while aerated medium exhibited gradual decrease during its growth phase compared to zero time. The highly significant free amino acids of $N$. muscorum was $15.9 \mathrm{mg}$ $\mathrm{g}^{-1}$ dry wt. at $6^{\text {th }}$ day and exceeded 4.7 folds of zero time under glucose medium followed by aerated enriched glucose medium $9.3 \mathrm{mg} \mathrm{g}^{-1}$ dry wt. at the same day and increased by 2.7 folds of zero time, followed by $6.3 \mathrm{mg}$ dry wt. at $6^{\text {th }}$ due to control condition. 
Table 3: Effect of different growth conditions on total carbohydrate of Anabaena laxa, Anabaena fertilissima and Nostoc muscorum, measured as $\mathrm{mg} \mathrm{g}^{-1}$ dry weight at different time periods.

\begin{tabular}{|c|c|c|c|c|c|c|}
\hline \multirow[b]{2}{*}{$\begin{array}{l}\text { Time period } \\
\text { (days) }\end{array}$} & \multicolumn{5}{|c|}{ Growth medium } & \multirow[b]{2}{*}{ LSD } \\
\hline & Control & Static glucose & Aerated & Molasses & $\begin{array}{l}\text { Aerated } \\
\text { enriched } \\
\text { glucose }\end{array}$ & \\
\hline & \multicolumn{5}{|c|}{ Anabaena laxa } & \\
\hline 0 & $213.4 \pm 2.5$ & $213.4 \pm 2.5$ & $213.4 \pm 2.5$ & $213.4 \pm 2.5$ & $213.4 \pm 2.5$ & 2.1 \\
\hline 2 & $309.5 \pm 2.4$ & $507.5 \pm 13.4$ & $265.7 \pm 11$ & $401.7 \pm 5.1$ & $312.8 \pm 15.8$ & 8.9 \\
\hline 4 & $324.7 \pm 6.4$ & $609.2 \pm 2.3$ & $295.1 \pm 4.9$ & $370.8 \pm 8.1$ & $596.4 \pm 19.4$ & 8.3 \\
\hline 6 & $324.8 \pm 3.5$ & $536.1 \pm 2.9$ & $244.5 \pm 10$ & $321.3 \pm 5.2$ & $572.6 \pm 7.3$ & 5.2 \\
\hline \multirow[t]{2}{*}{ LSD } & 3.3 & 5.8 & 6.5 & 4.6 & 10.7 & \\
\hline & \multicolumn{5}{|c|}{ Anabaena fertilissima } & \\
\hline 0 & $299.2 \pm 1.5$ & $299.2 \pm 1.5$ & $299.2 \pm 1.5$ & $299.2 \pm 1.5$ & $299.2 \pm 1.5$ & 1.3 \\
\hline 2 & $414.3 \pm 14.2$ & $604.2 \pm 12.8$ & $329.3 \pm 6.1$ & $390.9 \pm 14.8$ & $678.6 \pm 63.4$ & 24.9 \\
\hline 4 & $415.3 \pm 19.0$ & $715.8 \pm 18.6$ & $400.0 \pm 11.4$ & $493.8 \pm 27.7$ & $876.8 \pm 15.62$ & 15.7 \\
\hline 6 & $353.5 \pm 3.3$ & $593.5 \pm 2.2$ & $369.8 \pm 9.2$ & $610.6 \pm 14.3$ & $824.6 \pm 68.7$ & 25.9 \\
\hline \multirow[t]{2}{*}{ LSD } & 9.8 & 9.3 & 6.5 & 14.2 & 38.7 & \\
\hline & \multicolumn{5}{|c|}{ Nostoc muscorum } & \\
\hline 0 & $343.7 \pm 6.0$ & $343.7 \pm 6.0$ & $343.7 \pm 6.0$ & $343.7 \pm 6.0$ & $343.7 \pm 6.0$ & 5.0 \\
\hline 2 & $420.6 \pm 11.1$ & $341.5 \pm 11.5$ & $305.7 \pm 4.6$ & 0 & $528.5 \pm 29.9$ & 12.5 \\
\hline 4 & $443.4 \pm 9.5$ & $393.6 \pm 0.8$ & $306.2 \pm 1.4$ & 0 & $560.8 \pm 12.8$ & 5.9 \\
\hline 6 & $365.4 \pm 4$ & $452.4 \pm 3.5$ & $337.5 \pm 6.4$ & 0 & $831.2 \pm 55.4$ & 20.5 \\
\hline LSD & 6.7 & 5.5 & 4.1 & 2.5 & 26.4 & \\
\hline
\end{tabular}

Values are means of 3 replicates \pm SD

Table 4: Effect of different growth conditions on total soluble proteins of Anabaena laxa, Anabaena fertilissima and Nostoc muscorum, measured as $\mu \mathrm{g} \mathrm{mL}^{-1}$ of algal suspension at different time periods.

\begin{tabular}{|c|c|c|c|c|c|c|}
\hline \multirow[b]{2}{*}{$\begin{array}{l}\text { Time period } \\
\text { (days) }\end{array}$} & \multicolumn{5}{|c|}{ Growth medium } & \multirow[b]{2}{*}{ LSD } \\
\hline & Control & Static glucose & Aerated & Molasses & $\begin{array}{l}\text { Aerated } \\
\text { enriched } \\
\text { glucose }\end{array}$ & \\
\hline & \multicolumn{5}{|c|}{ Anabaena laxa } & \\
\hline 0 & $2.38 \pm 0.25$ & $2.38 \pm 0.25$ & $2.38 \pm 0.25$ & $2.38 \pm 0.25$ & $2.38 \pm 0.25$ & 0.21 \\
\hline 2 & $3.41 \pm 0.67$ & $1.83 \pm 0.11$ & $3.54 \pm 0.11$ & $8.01 \pm 0.19$ & $10.35 \pm 1.5$ & 0.61 \\
\hline 4 & $4.72 \pm 0.22$ & $3.04 \pm 0.19$ & $5.14 \pm 0.62$ & $6.45 \pm 0.41$ & $25.87 \pm 1.48$ & 0.62 \\
\hline 6 & $8.06 \pm 0.38$ & $2.13 \pm 0.36$ & $20.53 \pm 0.19$ & $3.14 \pm 0.29$ & $31.57 \pm 4.04$ & 1.5 \\
\hline \multirow[t]{2}{*}{ LSD } & 0.35 & 0.20 & 0.29 & 0.25 & 1.9 & \\
\hline & \multicolumn{5}{|c|}{ Anabaena fertilissima } & \\
\hline 0 & $0.99 \pm 0.17$ & $0.99 \pm 0.17$ & $0.99 \pm 0.17$ & $0.99 \pm 0.17$ & $0.99 \pm 0.17$ & 0.14 \\
\hline 2 & $1.83 \pm 0.08$ & $3.76 \pm 0.22$ & $1.02 \pm 0.11$ & $3.98 \pm 0.35$ & $1.79 \pm 0.16$ & 0.17 \\
\hline 4 & $2.97 \pm 0.48$ & $12.08 \pm 0.33$ & $2.13 \pm 0.30$ & $3.17 \pm 0.47$ & $3.26 \pm 0.50$ & 0.35 \\
\hline 6 & $2.57 \pm 0.40$ & $8.85 \pm 0.04$ & $8.18 \pm 0.85$ & $5.64 \pm 0.29$ & $4.88 \pm 0.48$ & 0.40 \\
\hline \multirow[t]{2}{*}{ LSD } & 0.27 & 0.18 & 0.38 & 0.28 & 0.30 & \\
\hline & \multicolumn{5}{|c|}{ Nostoc muscorum } & \\
\hline 0 & $0.20 \pm 0.08$ & $0.20 \pm 0.08$ & $0.20 \pm 0.08$ & $0.20 \pm 0.08$ & $0.20 \pm 0.08$ & 0.07 \\
\hline 2 & $1.04 \pm 0.19$ & $1.29 \pm 0.11$ & $0.11 \pm 0.08$ & 0 & $1.11 \pm 0.61$ & 0.24 \\
\hline 4 & $1.66 \pm 0.33$ & $3.49 \pm 0.67$ & $1.34 \pm 0$ & 0 & $2.74 \pm 1.72$ & 0.67 \\
\hline 6 & $1.98 \pm 0.47$ & $5.59 \pm 0.15$ & $5.91 \pm 0.33$ & 0 & $4.28 \pm 2.27$ & 0.86 \\
\hline LSD & 0.25 & 0.29 & 0.15 & 0.04 & 1.2 & \\
\hline
\end{tabular}

LSD; the least significant difference at $\mathrm{P} \leq 0.05$

Values are means of 3 replicates \pm SD 
Table 5: Effect of different growth conditions on free amino acids of Anabaena laxa, Anabaena fertilissima and Nostoc muscorum measured as $\mathrm{mg} \mathrm{g}^{-1}$ dry weight at different time periods.

\begin{tabular}{|c|c|c|c|c|c|c|}
\hline \multirow[b]{2}{*}{$\begin{array}{l}\text { Time period } \\
\text { (days) }\end{array}$} & \multicolumn{5}{|c|}{ Growth medium } & \multirow[b]{2}{*}{ LSD } \\
\hline & Control & Static glucose & Aerated & Molasses & $\begin{array}{l}\text { Aerated } \\
\text { enriched } \\
\text { glucose }\end{array}$ & \\
\hline & \multicolumn{5}{|c|}{ Anabaena laxa } & \\
\hline 0 & $12.40 \pm 0.19$ & $12.4 \pm 0.19$ & $12.4 \pm 0.19$ & $12.4 \pm 0.19$ & $12.4 \pm 0.19$ & 0.16 \\
\hline 2 & $13.1 \pm 0.16$ & $15.02 \pm 0.16$ & $7.16 \pm 0.20$ & $9.75 \pm 0.92$ & $20.92 \pm 3.68$ & 1.39 \\
\hline 4 & $13.21 \pm 1.24$ & $15.45 \pm 1.33$ & $3.05 \pm 0.45$ & $7.05 \pm 0.02$ & $23.77 \pm 1.66$ & 0.92 \\
\hline 6 & $13.53 \pm 0.38$ & $18.22 \pm 0.70$ & $3.13 \pm 0.07$ & $8.19 \pm 1.62$ & $40.49 \pm 4.78$ & 1.86 \\
\hline \multirow[t]{2}{*}{ LSD } & 0.54 & 0.62 & 0.22 & 0.77 & 2.6 & \\
\hline & \multicolumn{5}{|c|}{ Anabaena fertilissima } & \\
\hline 0 & $4.45 \pm 0.09$ & $4.45 \pm 0.09$ & $4.45 \pm 0.09$ & $4.45 \pm 0.09$ & $4.45 \pm 0.099$ & 0.08 \\
\hline 2 & $3.14 \pm 0.36$ & $26.66 \pm 0.70$ & $13.68 \pm 0.36$ & $28.07 \pm 1.0$ & $3.71 \pm 0.30$ & 0.49 \\
\hline 4 & $7.08 \pm 1.91$ & $29.71 \pm 0.10$ & $17.39 \pm 0.63$ & $28.85 \pm 1.0$ & $7.67 \pm 2.77$ & 1.3 \\
\hline 6 & $4.77 \pm 1.17$ & $27.46 \pm 0.38$ & $16.31 \pm 1.82$ & $35.32 \pm 0.34$ & $13.61 \pm 3.31$ & 1.46 \\
\hline \multirow[t]{2}{*}{ LSD } & 0.93 & 0.33 & 0.80 & 0.59 & 1.77 & \\
\hline & \multicolumn{5}{|c|}{ Nostoc muscorum } & \\
\hline 0 & $3.34 \pm 0.10$ & $3.34 \pm 0.10$ & $3.34 \pm 0.10$ & $3.34 \pm 0.10$ & $3.34 \pm 0.10$ & 0.08 \\
\hline 2 & $5.00 \pm 1.67$ & $9.99 \pm 1.35$ & $2.26 \pm 0.20$ & 0 & $5.54 \pm 0.48$ & 0.81 \\
\hline 4 & $5.40 \pm 0.39$ & $14.17 \pm 0.53$ & $2.27 \pm 0.16$ & 0 & $6.80 \pm 0.93$ & 0.42 \\
\hline 6 & $6.32 \pm 0.03$ & $15.87 \pm 1.51$ & $2.09 \pm 0.25$ & 0 & $9.30 \pm 1.45$ & 0.77 \\
\hline LSD & 0.70 & 0.86 & 0.16 & 0.04 & 0.73 & \\
\hline
\end{tabular}

LSD; the least significant difference at $P \leq 0.05$

Values are means of 3 replicates \pm SD

\section{DISCUSSION}

In this investigation, we observed that increasing glucose concentrations in the cyanobacterial medium up to $1 \%$ $(w / v)$ led to a gradual increase in total lipid content for Anabaena fertilissima and Nostoc muscorum. This observation coincided with Liang et al. (2009) who mentioned that maximum biomass density of Chlorella vulgaris was $2 \mathrm{~g} \mathrm{~L}^{-1}$ and lipid productivity (54 $\mathrm{mg} \mathrm{L}^{-1}$ day $\left.^{-1}\right)$ were obtained when cells grown with $1 \%(\mathrm{w} / \mathrm{v})$ glucose within 6 days. In addition, Bhatnagar et al. (2010) reported that lipid accumulation in $C$. minutissima cells was maximum (14.9\%) under light incubated glucosesupplemented conditions and minimum (5.4\%) in BG 11 medium without glucose. Matsuka et al. (1969) reported that glucose was mainly incorporated into lipids (particularly fatty acids) to optimize growth and production of desired chemicals from microalgae, it was essential to supply the right carbon source. So enriched glucose medium gives the highest lipid content rather than the other media. This explained why carbon sources assimilated through different metabolic pathways that mixotrophically under different culture conditions. In this context, Chu et al. (1995) studied the effect of different carbon sources on lipid production by Ankistrodesmus convolutes and concluded that stationary phase was the best growth phase for lipid production. In addition, Borowitzka (1994) established that lipid material are influence the biochemical composition of the investigated cyanobacterial strains. A. laxa, A. fertilissima and $N$. muscorum were grown photoautotrophically or secondary metabolites and thus are usually most abundant in stationary phase of growth. The present data showed that glucose $(1 \%, w / v)$ caused reduction of total lipid contents of $A$. laxa compared to concentration of $0.7 \%(w / v)$. This might be due to the inhibitory effect of glucose concentration. Liang et al. (2009) mentioned that, under mixotrophic growth conditions, glucose at $1 \%$ and $2 \%$ $(w / v)$ improved cell growth significantly compared with those at $5 \%$ and $10 \%(\mathrm{w} / \mathrm{v})$. On the other hand, increasing molasses concentrations in the cyanobacterial medium up to $0.7 \%(\mathrm{w} / \mathrm{v})$ led to a gradual increase in total lipid content for $A$. laxa and $A$. fertilissima. In accordance with our results, Yan et al. (2011) reported that increasing molasses led to increasing lipid content. Waste molasses hydrolysate was confirmed as a sole source of full nutrients to totally replace glucose-based medium in support of rapid growth and high oil yield from algae under optimized conditions. This was due to waste molasses containing both organic carbons and other nutrients as vitamins, trace elements and many other kinds of ingredients that consist mainly of $48 \%$ sugars (Crueger and Crueger, 1993; Yan et al., 2011). Our results revealed that $N$. muscorum was very sensitive to high molasses concentrations. It exhibited no growth on greater than $1 \%$ $(\mathrm{v} / \mathrm{v})$ of molasses medium. This might be attributed to the high osmotic pressure of sugars in raw molasses which suppress Nostoc growth. In accordance with Yan et al. (2011) who reported that $C$. protothecoides could not directly use molasses as organic carbon source because raw waste molasses contains $36.24 \%$ of sucrose. In addition, raw waste molasses contains colloidal and other impurities which might inhibit algal cell growth (Lee et al., 1999).

Static glucose medium $1 \%(\mathrm{w} / \mathrm{v})$, molasses medium $0.7 \%$ $(\mathrm{v} / \mathrm{v})$ and aerated enriched glucose medium $1 \%(\mathrm{w} / \mathrm{v})$ exhibited the highest values of both soluble and insoluble sugars for the experimental cyanobacterial species specially at early stationary phase or at stationary phase compared to control and aerated medium. Becker (1994) concluded that most studies on the biochemical 
production of algae and their analysis were carried out in stationary phase of growth period. These finding may be due to the dual benefit of both the presence of exogenous glucose sugar plus the fixed carbon dioxide which is present normally in air and the agitation effect caused by bubbling which increased the amounts of oxygen present in the growth medium that enhanced mass production and consequently led to high carbohydrate content. These finding are in accordance with Chu et al. (1995), but only at glucose levels of 0.25 and $0.5 \%(w / v)$. Also, Liang et al. (2009) reported that bubbling air into C. vulgaris culture exerted positive effect on cell growth.

The present study revealed that $A$. laxa exhibited the highest significant protein production under aerated enriched glucose medium at $6^{\text {th }}$ day compared to $A$. fertilissima and $N$. muscorum. It seemed that this medium condition was favorable for protein production. This was attributed to the high content of exogenous carbon source (glucose present in the medium) plus the fixed nitrogen gas which constitutes about $70 \%$ of air presented to growth medium via bubbling technique. Nitrogen fixation was a normal biochemical process that takes place in heterocystous filamentous microalgae as the medium BG110 was free of nitrogen. So, both carbon and nitrogen sources were available in algal media with large proportions and consequently channeled to protein or free amino acids synthesis.

The obtained results showed that any changes in growth condition led to a significant effect on total free amino acids content. High proportion of free amino acids were obtained under aerated enriched glucose medium for $A$. laxa. This finding was due to the richness of this medium with both exogenous carbon source and fixation of nitrogen into ammonium containing compounds as described before. The utilization of molasses medium exerted a pronounced effect on total free amino acids of A. fertilissima, this was due to the luxury of molasses with both organic and nitrogenous compounds. This finding was in accordance with Teclu et al. (2009) and Yan et al. (2011) who reported that waste molasses itself contains nitrogenous compounds (2-6\%), which was apparently sufficient in support of algal growth.

\section{CONCLUSION}

The investigated cyanobacterial strains showed different response against the type of medium nutrition, where they succeeded to grow under both autotrophic and mixotrophic growth conditions. Aerated enriched glucose medium $(1 \%, w / v)$ was the best growth medium condition used in the present study. The highest lipid content, total carbohydrates, total soluble proteins and total free amino acids were achieved under the medium incorporated with glucose.

\section{REFERENCES}

Allen, M.M. and Stanier, R.Y. (1968). Selective isolation of blue-green algae from water and soil. Journal of General Microbiology 51(2), 203-209.

Barnes, H. and Blackstock, J. (1973). Estimation of lipids in marine animals and tissue. Detailed investigation of the sulphophosphovanilun method for total lipids. Journal of Experimental Marine Biology and Ecology 12, 103-118.

Becker, E.W. (1994). Microalgae: Biotechnology and Microbiology. Baddiely, J. et al. (eds.). Cambridge Univ. Press, Cambridge, New York. pp230

Borowitzka, M.A. (1994). Large-scale algal culture systems: the next generation. Australasian Biotechnology 4, 212-215.

Droop, M.R. (1974). Heterotrophy of carbon. In: Algal physiology and biochemistry. Stewart, W.D.P. (ed.). Botanical Monographs; University of California Press, Berkeley and Los Angeles. pp. 530-559.

Bhatnagar, A., Bhatnagar, M. and Chinnasamy, S. (2010). Chlorella minutissima-A promising fuel alga for cultivation in municipal wastewaters. Applied Biochemistry and Biotechnology 161, 523-536.

Borsari, R.R.J., Morioka, L.R.I. and Ribeiro, M.L.L. (2007). Mixotrophic growth of Nostoc sp. on glucose, sucrose and sugarcane molasses for phycobiliprotein production. Revista Tecnologica, Maringá 29(1), 9-13.

Chen, F. and Zhang, Y. (1997). High cell density mixotrophic culture of Spirulina platensis on glucose for phycocyanin production using a fed-batch system. Enzyme and Microbial Technology 20, 221-224.

Chu, W.L., Siew-Moi, P., and Swee-Hock, G. (1995). Influence of carbon source on growth, biochemical composition of Ankistrodesmus convolutus. Journal of Applied Phycology 7, 59-64.

Crueger, W. and Crueger, A. (1993). Biotecnologia: manual de microbiologia industrial. Zaragoza, España : Acribia, S.A. (ed.) 413p.

Ducat, D.C., Way, J.C. and Silver, P.A. (2011). Engineering cyanobacteria to generate high-value products. Trends in Biotechnology 29(2), 95-103.

Habib, M.A.B., Parvin, M. and Huntington, T.C. (2008). A review on culture, production and use of Spirulina as food for humans and feeds for domestic animals and fish. FAO Fisheries and Aquaculture Circular No. 1034, 33p.

Lee, P.C., Lee, W.G. and Lee, S.Y. (1999). Effects of medium components on the growth of Anaerobiospirillum succiniciproducens and succinic acid production. Process Biochemistry 35, 49-55.

Lee, Y.P. and Takahashi, T. (1966). An improved colorimetric determination of amino acids with the use of ninhydrine. Analytical Biochemistry 14, 71-77.

Liang, Y., Nicolas, S. and Cui, Y. (2009). Biomass and lipid productivities of Chlorella vulgaris under autotrophic, heterotrophic and mixotrophic growth conditions. Biotechnolgy Letters 31, 1043-1049.

Lowry, O.M., Rosebrough, N.J. and Farr, L.A. (1951). Protein measurements with the folin phenol reagent. The Journal of Biological Chemistry 193, 256-257. 
Marquez, F.J., Nishio, N. and Nagai, S. (1995). Enhancement of biomass and pigment production during growth of Spirulina platensis in mixotrophic culture. Journal of Chemical Technology and Biotechnology 62, 159-164.

Matsuka, M., Miyachi, S. and Hase, E. (1969). Further studies on the metabolism of glucose in the process of glucose-bleaching of Chlorella protothecoides. Plant and Cell Physiology 10, 513-526.

Roger, S.L. and Burns, R.G. (1994). Changes in aggregate stability, nutrient status, indigenous microbial populations, Nostoc muscorum. Biology and Fertility of Soils 18, 209-215.

Singh, A. and Olsen, S.I. (2011). A critical review of biochemical conversion, sustainability and life cycle assessment of algal biofuels. Applied Energy 88, 3548-3555.

Teclu, D., Tivchev, G. and Laing, M. (2009). Determination of the elemental composition of molasses and its suitability as carbon source for growth of sulphate-reducing bacteria. Journal of Hazardous Materials 161, 1157-1165.

Tuchman, N.C. (1996). The role of heterotrophy in algae. In: Algal Ecology. Stevenson, R.J. (ed.). Academic Press, San Diego. pp. 299-318.

Yan, D., Lu, Y., Chen, Y.F. and Wu, Q. (2011). Waste molasses alone displaces glucose-based medium for microalgal fermentation towards cost-saving biodiese production. Bioresource Technology 102, 6487-6493.

Yemm, E. and Willis, A. (1954). The estimation of carbohydrates in plant extracts by anthrone. Biochemical Journal 57, 508-514. 